\title{
Cost and Benefit Evaluation of Graffiti Countermeasures on the Nevada Highways
}

\author{
Hualiang Teng1* ${ }^{*}$ Anil Puli' , Boniphace Kutela1, Yongjun $\mathrm{Ni}^{2}$, Bingyi $\mathrm{Hu}^{3}$ \\ ${ }^{1}$ Department of Civil and Environmental Engineering, University of Nevada, Las Vegas, USA \\ ${ }^{2}$ School of Civil Engineering, Beijing Jiaotong University, Beijing, China \\ ${ }^{3}$ School of Computer and Informational Technology, Beijing Jiaotong University, Beijing, China \\ Email: ‘hualiang.teng@unlv.edu, chaseurpuli@gmail.com, kutela4@gmail.com, hby@bjtu.edu.cn
}

How to cite this paper: Teng, H.L., Puli, A., Kutela, B., Ni, Y.J. and Hu, B.Y. (2016) Cost and Benefit Evaluation of Graffiti Countermeasures on the Nevada Highways. Journal of Transportation Technologies, 6, 360-377.

http://dx.doi.org/10.4236/jtts.2016.65031

Received: April 18, 2016

Accepted: September 27, 2016

Published: September 30, 2016

Copyright (๑) 2016 by authors and Scientific Research Publishing Inc. This work is licensed under the Creative Commons Attribution International License (CC BY 4.0).

http://creativecommons.org/licenses/by/4.0/ (c) (i) Open Access

\begin{abstract}
Nevada is one of the major states that are currently suffering from graffiti problem. It was estimated that graffiti costs Southern Nevada around $\$ 30$ million per year. The major highway structures that were suffering from graffiti were bridges, sound walls, retaining walls and traffic signs. Removing graffiti from these infrastructures was a big challenge to the maintenance division of Nevada Department of Transportation (NDOT). Thus, the department was looking for cost effective proactive countermeasures to prevent graffiti on highway infrastructure. This study first identified a spectrum of proactive countermeasures, and then evaluated them by conducting a costbenefit analysis. Pedestrian fencing and chain link fence were found to be cost effective countermeasures for preventing graffiti on bridges and sound walls. However, for relative long sound walls, the chain link becomes less cost effective. Rat guard was found to be cost effective for road signs; however, it was more useful for traffic signs that are located in the area where the taggers cannot find the way to bypass the rat guard. Coating and landscaping were found to be cost effective for small structures. The security camera countermeasure was not cost effective at the locations where the reduction in graffiti was small. The software for spectrometers was relatively high cost and might hinder the cost effectiveness of this countermeasure. To reduce the cost of the software, developing the software internally could be adopted. And finally, the electronic database was recommended since it was not difficult to develop and maintain.
\end{abstract}

\section{Keywords}

Cost and Benefit, Evaluation, Graffiti, Graffiti Countermeasures, Highway

Infrastructure 


\section{Introduction}

Graffiti can be described as any unauthorized inscription, word, figure, picture, or design that is sprayed, marked, cut, posted, pasted or otherwise affixed, drawn or painted on any surface of public or private property [1]. Initiated by gangs in New York in 1960s, graffiti vandalism is an ever-growing and expensive problem in the United States [2]. The problem was escalated by the introduction of spray paints, permanent markers and other vast technologies. The harm caused by graffiti is in terms of property damage as well as fear of crime, which is the main focus for state and central government [3]. Graffiti on the highways is not only an eyesore to the traveling public, it presents a hazard to the perpetrator and a liability exposure for transportation agencies because highway structures span high elevations and are in close proximity to motor vehicle traffic [4].

The highway facilities affected by graffiti include bridges, sound walls, retaining walls, traffic signs and sign poles. The graffiti on these facilities are cleaned by state Departments of Transportation (DOTs). The removal techniques depend on the types and locations of surfaces affected by graffiti and the type of paints used by the taggers. Painting over, water blasting, sand blasting, and chemical removal are the popular removal techniques adopted by different states.

A study in [4] found that, approximately $12 \%$ of the highways are affected by graffiti. Highway structure's visibility, surface properties and accessibility were identified as the attractive factors to taggers. This study recommended all the state highway agencies to maintain the track record of graffiti-related costs as a separate cost from other highway maintenance activities, by which the magnitude of the problem can be determined and the removal and prevention measures may be implemented accordingly.

Currently, Nevada is one of the major states suffering from graffiti problem. It was estimated that graffiti damage costs in Southern Nevada was around \$30 million a year. Particularly, graffiti vandalism on the highway infrastructures of Nevada has become an eyesore to the Nevada Department of Transportation (NDOT). The major highway structures that are suffering from graffiti in Nevada are bridges, sound walls, retaining walls and traffic signs. Removing graffiti from these infrastructures is a big challenge to the maintenance division of NDOT. "Paint over" was the method adopted by NDOT to remove graffiti. NDOT has also tried using anti-graffiti coatings but these are proved to be labor intensive and less effective. At some places, as soon as the removal team removes graffiti, taggers are repeating the vandalism in the same places to represent their gang reputation. To avoid this repeating vandalism, NDOT is looking for permanent proactive countermeasures to prevent graffiti on highway infrastructure. The current problem is to develop anti-graffiti countermeasures to prevent graffiti on highway structures of Nevada.

The objective of this study is to evaluate the anti-graffiti countermeasures using costbenefit analysis. To identify a spectrum of graffiti countermeasures, literature review was conducted, the research team visited some selected cities and counties and a survey about the practices of preventing graffiti by state DOTs was conducted. Data on graffiti 
on the major highway facilities in the Las Vegas and Reno areas were collected. For each of the identified countermeasures, relevant cost and benefit data were collected from different sources and a cost and benefit study was conducted correspondingly for each identified countermeasure.

The remaining part of the paper is organized as follows. The first section presents a literature review on the countermeasures studied before. In the second section, the methodology adopted in this study is described. The third section provides an introduction on how the countermeasures are identified. In the fourth section, each of the identified graffiti countermeasures is analyzed in terms of their costs and benefits. The last section provides conclusions on which countermeasures should be recommended in practice.

\section{Literature Review}

Graffiti varies from a bare, utilitarian scrawl meant to convey a message to large attractive murals that take 20 to 30 cans of paint [5]. In general, there are five major types of graffiti: 1) Hip-hop graffiti, 2) Gang graffiti, 3) Conventional graffiti, 4) Ideological graffiti, and 5) Stenciling.

The highway structures affected by graffiti include bridges, sound walls, retaining walls, traffic signs and sign poles. Around bridges, graffiti can be found on the piers, abutments, girders and beams of the bridges. However, the graffiti which are clearly visible to motorists are usually found on the component like beams runs across the direction of traffic. The taggers access the bridge components from the sides or top of the bridge. Sound walls are textured walls that are to absorb the sound from the highway traffic and reduce the noise impacts to the adjacent houses. They run along roadway and thus can be tagged by taggers stopping their vehicles on the shoulder of roadway. Retaining walls are either in association with bridges or at isolated location. Like sound walls, retaining walls not associated with a bridge also run along highways, and thus are tagged in the similar way as sound walls. Traffic signs are susceptible to graffiti because the messages on them are viewed directly by motorists. To tag traffic signs, taggers usually climb the mounting poles and then reach to the signs.

Graffiti countermeasures for highway facilities found in the literature and the survey to DOTs include: 1) Employ anti-graffiti coatings, 2) Design modifications to control access, 3) Surveillance, 4) Rapid removal, 5) Graffiti tracker.

Anti-graffiti coatings which are either sacrificial or non-sacrificial (permanent) can be applied to the surfaces in order to resist graffiti. Sacrificial anti-graffiti coating are designed to come off the surface during graffiti removal process [6] that is performed by using high-pressure hot water. Non-sacrificial or permanent anti-graffiti coatings are usually water-based acrylic or solvent-based polyester urethanes. While water based coatings are less expensive and have no adverse effect, they don't last longer [7].

The access to bridges, sound walls, retaining walls, and traffic signs are controlled in different ways for anti-graffiti purpose. Bridges are usually fenced on the top to prevent the access of taggers to bridge decks, and their corners are chain link fenced to deter the 
access of taggers to the outside girders. Apart from chain link, landscaping by plants like ivy, wines, bushes and thorny shrubs that need water or aggregation of stones piling up along sound walls has also been shown to be effective in preventing graffiti for sound walls. However, ivy and vines take several years to completely cover a wall and shrubs will not cover the entire sound walls. Like sound walls, unfenced retaining walls are easily attacked by taggers. Fencing and anti-graffiti coatings are the obvious options to prevent graffiti on retaining walls. The popular countermeasures for graffiti on traffic signs are installation of devices such as Rat Guard, concertina wire or barbwire, Graffiti Shields, and Nugard on sign pole or the panel of sign to prevent taggers from accessing the signs [8]. According to NDOT experience, rat guards are good in mitigating graffiti and it was found that $90 \%$ of the graffiti was mitigated on the signs, where rat guard was installed.

Surveillance camera is a commonly employed countermeasure to graffiti in graffitiprone sites. These cameras are connected to closed circuit televisions that are under real-time observations. However, sometimes the taggers may either damage the cameras or wear the hood and make graffiti on the nearby structures. This would make prosecution from videotape evidence very difficult, reducing the deterrence effect of the cameras [8].

Rapid removal of graffiti is the most effective method to prevent future vandalism. This is frequently cited in the literature concerning graffiti because it nullifies the notoriety or "fame" sought by taggers and shows taggers that the site is being watched [9].

Graffiti Tracker is a program to analyze the graffiti made by taggers and finding the taggers, who made the graffiti. The graffiti pictures have to be uploaded to the software of the tracker program. The tracker program identifies the graffiti made by the same taggers and then it will mark the locations having same name of tag. Thus, it can locate the areas, where taggers live so that law enforcement officers can arrange extra surveillance in those areas.

\section{Methodology}

To achieve the objective of this study, a two-step process was applied. The first step was the identification of a spectrum of countermeasures that are possible for preventing graffiti on highway infrastructure. The second step was to evaluate the countermeasures identified in the first step by conducting a cost-benefit analysis.

A questionnaire (see Appendix) was designed and distributed to 50 states. The questionnaire includes groups of questions with a focus that was given to the graffiti prevention measures. These measures include those for preventing touching and accessing of vandals to the highway structures, design policies, usage of security cameras for surveillance, mutual co-operation between the agencies such as state Department of Transportations (DOTs), local governments, communities and schools, types of educational activities to children to fight against graffiti, law enforcement activities to taggers, and criteria of punishment. Firsthand information about the practices of anti-graffiti was collected through visiting Caltrans, Arizona Department of Transportation (ADOT), 
and NDOT. Data were collected on the number, the type and the amount of graffiti, the existence of fencing and accesses, and the land use type around the infrastructures such as bridges, sound wall, retaining walls, and traffic sign in the Las Vegas and Reno areas in Nevada

Cost and benefit analysis was conducted to pedestrian fence, corner fencing, rat guard/shields, coating, security cameras, electronic spectrometers, and graffiti database countermeasures. The costs include capital, installation and maintenance costs. The capital and installation costs are onetime costs while the maintenance costs incurred over the lifetime of these countermeasures. The maintenance costs over the lifetime were converted to the present value with an interest rate $(i)$ of 0.08 and number of years (n) being the life time of a particular object. The present values of the maintenance costs were calculated by using the following formula [10].

$$
P V_{M C}=U S_{M C} \times\left(\frac{(1+i)^{n}-1}{i(1+i)^{n}}\right) \text {. }
$$

The benefits, except for the coating, were primarily the saving of costs for graffiti removals with the adoption of the countermeasures. In the case of the coating countermeasure, the benefits were more about the saving for restoring the properties to be damaged by graffiti. For the electronic spectrometer countermeasure, the benefits were provided in a qualitative manner. In the case of electronic database, the benefits are presented as the usefulness of the database. In addition, the ease of developing such a database was also addressed which is helpful to show both the costs and benefits sides.

\section{Identification of Graffiti Countermeasures}

From the literature review, survey to state DOTs, visits to cities, counties and DOTs, and the inventory data analysis, a spectrum of countermeasures preventing graffiti on highways were identified [11]. The identified countermeasures together with the countermeasures selected for cost benefit analysis are presented in Figure 1. As a rule of thumb, any countermeasure with benefit cost ratio greater than one is cost effective.

\section{Cost and Benefit Study}

\subsection{Pedestrian Fencing to Bridges}

In this study the lifetime of pedestrian fence was considered to be 25 years with once damage occurrence per year. For a bridge with 200 feet long and 5.8 feet high fence on the top of a bridge, the capital and installation costs were found to be $\$ 3132$ and $\$ 7192$, respectively, while the yearly maintenance cost was found to be $\$ 148.8$. With uniform series present worth factor of 10.67 and the interest rate of 0.08 , the total net present value of the total costs becomes $\$ 11,912$.

The benefit of using pedestrian fencing in monetary terms was calculated as the difference between graffiti removal cost without fencing and with fencing. The inventory data revealed that the average area of graffiti on a bridge without fencing is 28.9 while that with fencing is 4.76 square feet per year and the average number of graffiti for 


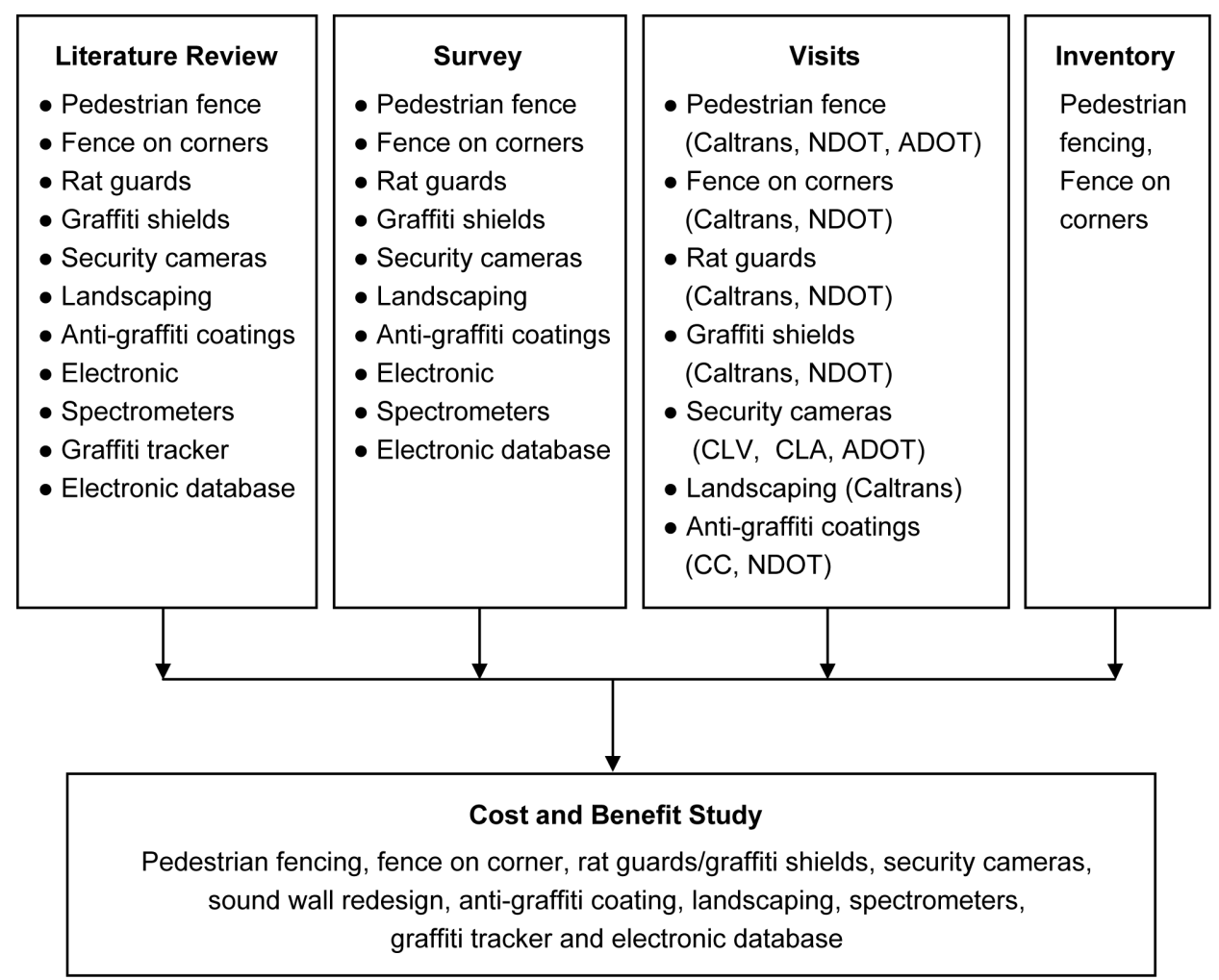

Figure 1. Countermeasures identified from different sources.

bridges without and with fencing is 3.95 and 0.46 . The net present value of the benefit was found to be $\$ 47,309$, which resulted in effective benefit and cost ratio of 3.97.

According to NDOT, having the number of graffiti reduced by $90 \%$ is an objective that can be reasonably expected for a new countermeasure. The sensitivity analysis results show that, the higher the interest rate the lower is the benefit cost ratio (see Figure 2 ), and the higher the percentage reduction in graffiti the higher is the benefit cost ratio (see Figure 3).

\subsection{Chain Link Fence on the Corners of the Bridge}

The capital cost to buy the chain link fence is $\$ 1.2$ per square feet [12]. Assuming a chain link fence of 25 feet long and 5.8 feet high is installed on each of the four corners of a bridge in the Las Vegas and Reno area, the total of capital, installation, and the 25 years maintenance costs at the present value was found to be $\$ 5880$.

The inventory data shows that the average number of graffiti cases on the retaining wall, while there was no chain link fence on the corners of a bridge was 0.73 per year, each with an average area of 3.43 square feet and eighty percent $(80 \%)$ reduction in number of number of graffiti cases. Therefore, the benefit at the present value was found to be $\$ 7475$ which yields the benefit and cost ratio 1.271 , which is greater than one.

The length of the chain link fence is critical in determining the benefit and cost ratio. The total length of the chain link fence was then varied between 100 feet and 800 feet 


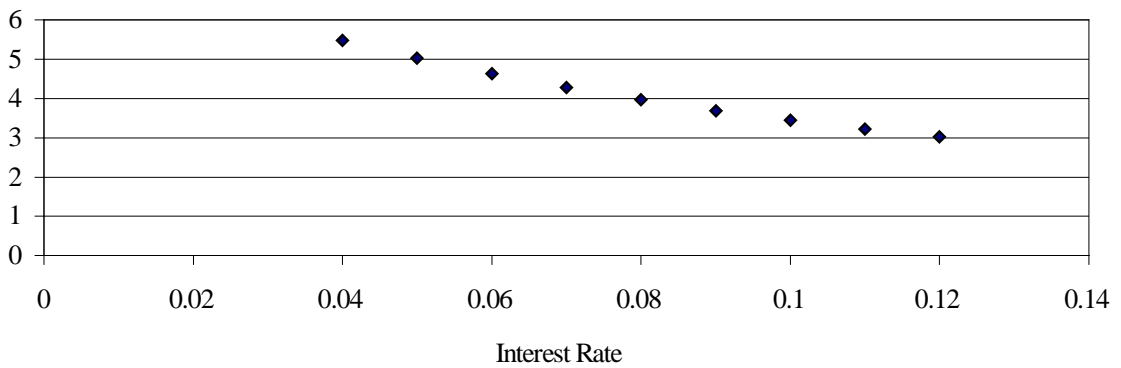

Figure 2. Benefit and cost ratio versus interest rate for the pedestrian fencing on bridges.

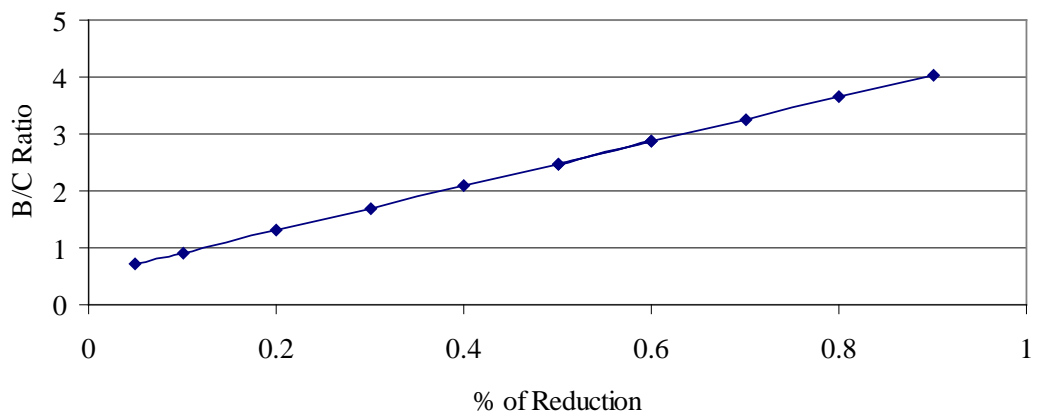

Figure 3. The $\mathrm{B} / \mathrm{C}$ ratio versus the effectiveness of the pedestrian fencing on bridges.

for sensitivity analysis. As the total length increases at bigger values, the benefit with the total $80 \%$ reduction of graffiti would be balanced out. Since the benefit and cost ratio decreases sharply when the length increase at a small value, the chain link fence is sensitive to its length (see Figure 4). Similar results were observed for higher interest rates (see Figure 5). Thus, the chain link fence with short length can always be cost effective for interest rates less than $12 \%$.

\subsection{Rat Guards/Graffiti Guards}

Currently NDOT is manufacturing Rat Guard itself. Thus, Capital, Installation and the five (5) year Maintenance Costs for Rat Guard was found to be \$349.

From the NDOT, Caltrans experience and site visits, the five years present value cost of removing graffiti on the four square foot overhead signs with no rat guard which was estimated to have 2.4 graffiti cases per year was found to be $\$ 11,355$. The number of graffiti can be reduced by $90 \%$ on the overhead signs if rat guard is installed. The total life time graffiti removal cost on overhead signs with rat guard was found to be $\$ 1135$. The benefit of using rat guard was found to be $\$ 10,219$. Thus, the resulted benefit and cost ratio was 29.22, which is much greater than one.

In the cost-benefit analysis discussed above, the frequency of graffiti when there is no rat guard may vary significantly dependent upon the location where a traffic sign is installed. In the calculation of the benefits above, the frequency considered was 2.4 per year which is equivalent to 12 graffiti cases for five year. Sensitivity analysis was conducted for variable graffiti frequency. Results in Figure 6 suggest that rat guard is very commendable as for a graffiti countermeasure even at low frequency of graffiti. 


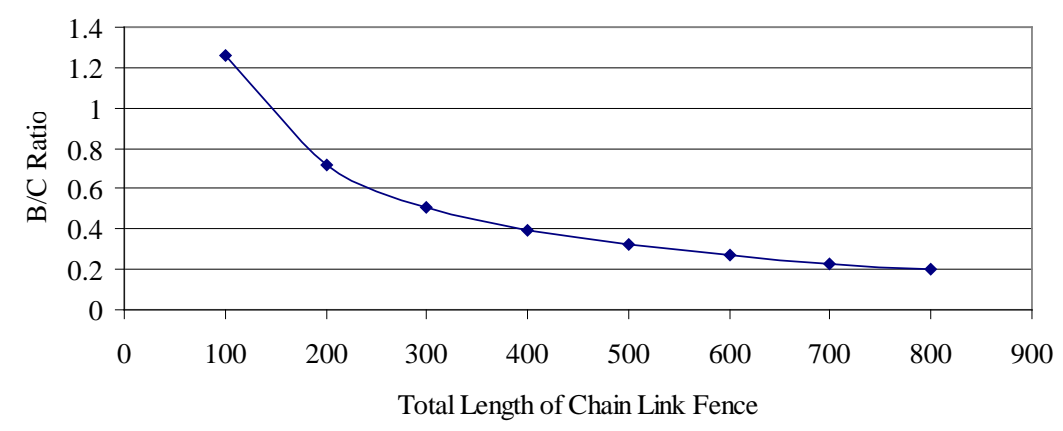

Figure 4. The benefit and cost ratios versus the total length of chain link fence.

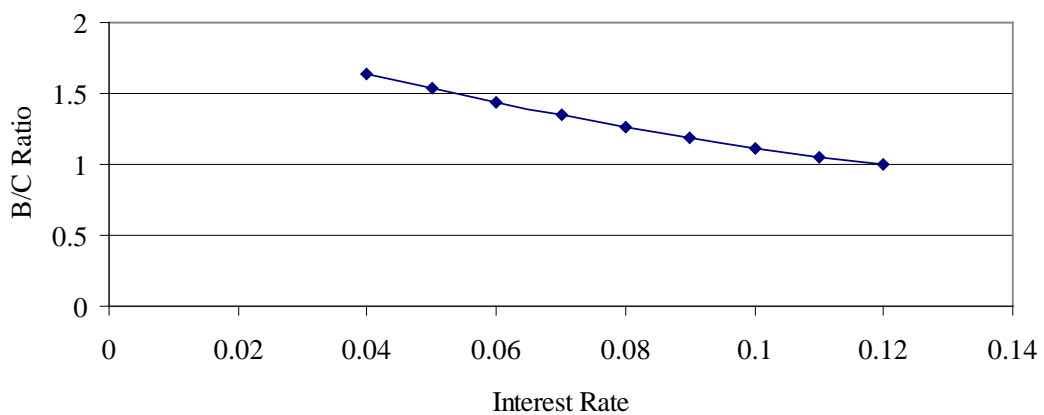

Figure 5. Benefit and cost ratio versus different interest rate for chain link fence.

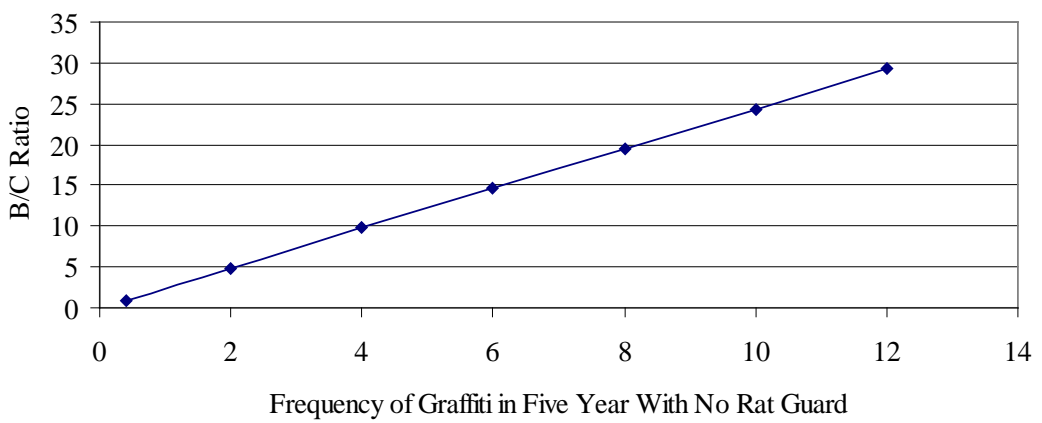

Figure 6. Benefit and cost ratio versus frequency of graffiti cases with No Rat Guard.

In practice, the overhead traffic signs have to be replaced if they are attacked multiple times. This difference in the cost for sign replacements is considered in the calculation of cost and benefit for rat guard. According to NDOT, the replacement cost per traffic sign was assumed to be $\$ 400$. The replacement cost over five years for a sign post that can be attacked three times per year was $\$ 1276$ when there is no rat guard installed. If a rat guard is installed, the total replacement cost in five years can be reduced to $\$ 127$ since the possibility of taggers to attack the signpost is only $10 \%$. By adding the sign replacement cost, the total removal/replacement costs on a sign become $\$ 12,632$ and $\$ 1263$, respectively, for the case of without and with rat guard. Therefore, the corresponding benefit and cost benefit ratio were $\$ 11,368$ and 32 respectively. The ratio is even greater than that when the sign replacement is not considered because that the cost for replacing sign would also be reduced if less number of graffiti cases occurs. 
With varying interest rates, the sensitivity analysis revealed that the benefit and cost ratio does not change dramatically with the interest rate (Figure 7), which implies that Rat Guard is not sensitive to interest rate.

\subsection{Redesign Sound Wall to Accommodate Rat Guard}

Taggers may climb over the steel plate of rat guard from a nearby facility such as sound wall to tag a traffic sign. As such, rat guard would become useless for preventing graffiti. To make rat guard to be effective in preventing graffiti, it is needed to separate nearby highway facilities such as sound wall from the pole of overhead traffic sign for a certain distance. However, there are issues like implementation of uniform building code (UBC) for reconstructing of old sound wall. For this reason, the concept of moving the sound wall to accommodate rat guard is suggested to the new sound walls that are in design stage.

\subsection{Security Cameras}

According to sources from the City of Las Vegas, the capital cost for purchasing such a system was $\$ 6000$, and the installation cost is assumed $\$ 200$. No operation and maintenance costs were assumed for the camera system as the cameras have self-battery systems and have a five-year warranty.

As per the City of Las Vegas, in a five years period, the cost of removing graffiti in a typical location where the occurrence of graffiti vandalism was high was $\$ 76,660$. After the installation of a camera, the cost was reduced to approximately $\$ 2395$. Thus, the savings for installing camera was $\$ 74,265$. Thus, the benefit and cost ratio becomes 11.97. Note that, only one camera was assumed for this calculation. If more cameras are used, the frequency of graffiti on the ranges covered by these cameras would be different. Then, different benefit and cost ratio may be resulted

From Figure 8 of the sensitivity analysis, it can be seen that the benefit cannot balance out the cost of having the camera when the cost for removing graffiti is less than $10 \%$. The change in the benefit and cost ratio responding to different interest rate is very small (11.92 to 12.02 , see Figure 9 ). Based on the analysis, it was concluded that camera is a cost effective countermeasure for graffiti.

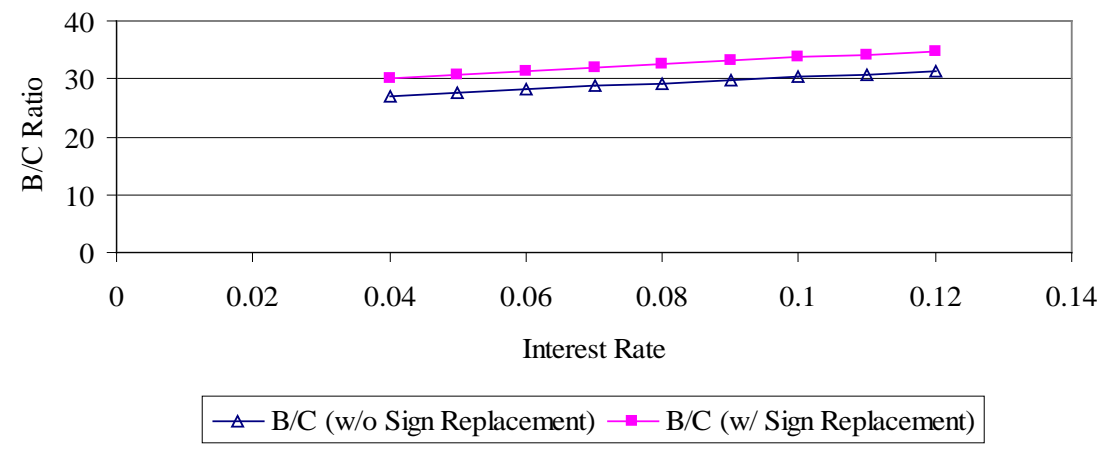

Figure 7. Benefit and cost ratio versus interest rate for rat guard. 


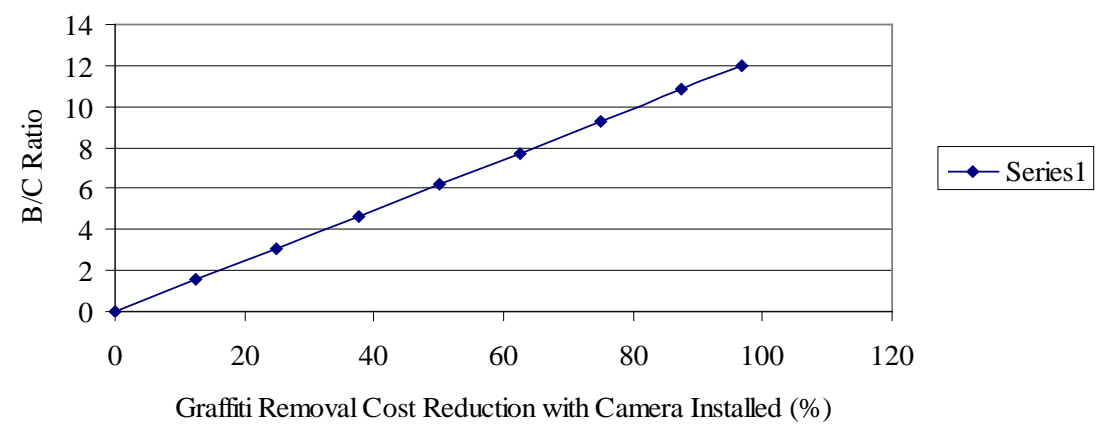

Figure 8. Benefit and cost ratio versus graffiti removal cost reduction with camera installed.

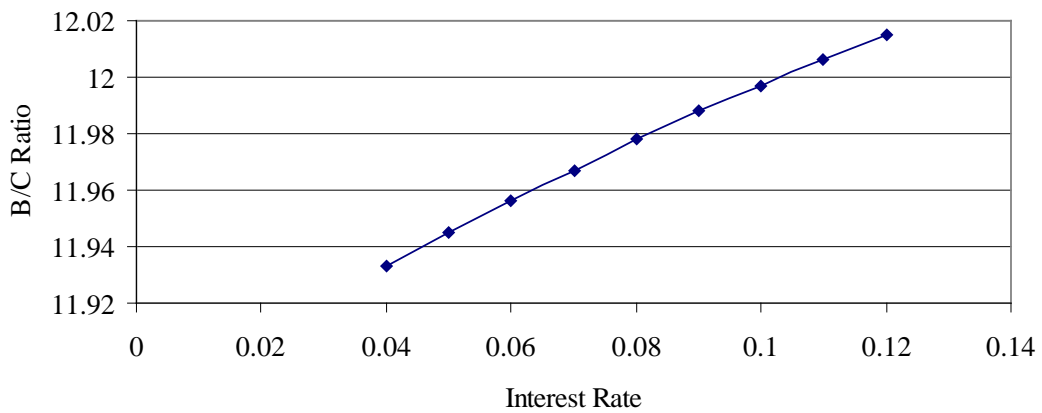

Figure 9. Benefit and cost ratio versus interest rate for camera.

\subsection{Anti-Graffiti Coatings}

A 216 square feet sculpture, whose cost was $\$ 20,000$, was considered for this study. According to NDOT, the total cost of applying anti-graffiti coatings, installation and lane closures costs was $\$ 7366$. Assuming the same graffiti removal cost while anti-graffiti coatings are applied to be $\$ 1169$, the total costs becomes $\$ 8532$. If the sculpture has not treated with anti-graffiti coatings, the graffiti on it cannot be removed without damaging it. In this case sculpture has to be replaced, which costs $\$ 20,000$. So, the benefit of applying anti-graffiti coatings can be viewed as the sculpture cost that is $\$ 20,000$. Therefore, the benefit cost ratio is calculated was found to 2.34 , which is greater than one.

\subsection{Landscaping to Sound Walls}

Assuming the same graffiti removal costs mentioned in the above section, the annual graffiti removal costs is $\$ 1169$ if there is no landscaping to the sound wall for which no coating is applied. The present value for graffiti removal costs over the 15 years lifetime of landscaping is $\$ 10,008$. It is also assumed that graffiti will be completely reduced on the sound walls, if the landscaping is provided. A graffiti countermeasure will be cost effective if the cost of the project doesn't exceed $\$ 10,008.46$. Under this countermeasure, supplying water is the critical issue especially when the vegetation is used.

\subsection{Electronic Spectrometers}

According to the City of Phoenix, spectrometers are the electronic machines that costs 
around $\$ 5000$ apiece and can be purchased with a five-year warranty. Software is needed for the color matching process and this software costs around $\$ 40,000$ as a one-time investment. The benefits of using spectrometers may not be readily quantifiable in monetary terms. Improving the value of community, lowering the crime related activities, preventing children and youth from creating more graffiti are few benefits worth a mention. Therefore, the benefits for having consistent colors when removing graffiti, using electronic spectrometers are desired.

\subsection{Graffiti Tracker}

Under this countermeasure, an agency has to pay tracker system one dollar for each graffiti case. If 60,000 graffiti cases are found by an agency in a year, this agency has to upload these 60,000 to the tracker system and pay $\$ 60,000$ to the company owning the system. This cost is significant from the perspective of public agencies. On the other hand, according to Clark County, it is not difficult for an experienced anti-graffiti staff to find the same intelligence from the database each agency maintains, which makes the Tracker system less valuable to the anti-graffiti team.

\subsection{Electronic Database}

Maintaining electronic database of graffiti is a good resource for finding the locations, where specific measures need to be improved for mitigating and preventing graffiti. This database may include the graffiti name and type, location, surface type, removal method used and removal costs etc. The benefits of maintaining database include scheduling daily operations, finding statistics of the graffiti and removal costs and catching taggers by providing extra surveillance. On the other hand, it may cost about $\$ 50,000$ to build such a database system by a professional firm. Considering the cost and benefit, it is perceived that the benefit for having such a database is greater than without. Thus, it is recommended to have a database to be available.

\section{Conclusions and Recommendations}

In this study, countermeasures for graffiti were evaluated by using cost and benefit analysis. A literature review was first conducted to identify the countermeasures that were available. Most of the information was obtained from websites that were established by either public or private agencies both in the United States and other countries.

The cost and benefit analysis for pedestrian fencing indicates that it is very cost effective in preventing graffiti. Thus, fencing is recommended for bridges that have potential place for graffiti. The chain link fence is cost effective only when the length of the chain link is relatively short. So, it is recommended to be implemented with the consideration of the length especially for sound walls. Rat guards were found to be cost effective. One problem found for these countermeasures is that taggers may step on top of the metal plate from nearby facilities such as sound walls. Thus, there is a need to inform the design division of such an issue related to graffiti.

Coating has been found to be cost effective for a small sized infrastructure like 
sculpture or a well-designed picture on the retaining wall around a bridge. However, for large size structures like a whole segment of sound wall, coating is not cost effective. Landscaping has been proved to be effective for sound walls and retaining walls in other state DOTs such as California. However, its cost effectiveness is limited. Security cameras are cost effective in general conditions. However, they may not be cost effective if the system fails at high frequency or the reduction in graffiti is small. Spectrometers are starting to be adopted by more cities for anti-graffiti in recent years. Even though the cost for the needed software of spectrometer is relatively high, it may be worthy to be implemented. To reduce the cost of the software, developing the software internally can be tried. An electronic database is recommended since it is not difficult to develop and maintain.

\section{References}

[1] Graffiti Control Program (2000) What Is Graffiti? The City of San Diego Website: https://www.sandiego.gov/police/services/prevention/tips/graffiti

[2] Wylie, S. (1999) Graffiti Vandalism: The Current Situation in Christchurch and Potential Countermeasures. Report Submitted to Christchurch City Council.

[3] Callinon, R. (2002) Dealing with Graffiti in New South Wales. Briefing Paper Submitted to Parliament of New South Wales.

[4] Eck, R.W. and Martinelli, D.R. (1998) Assessment and Mitigation Measures for Graffiti on Highway Structures. Transportation Research Record, 1642, 35-42.

[5] Claire-King, B. (2003) Fates Worse Than Death: The Role Playing Game. Vajra Enterprises, 344-345.

[6] (2008) GraffitiHotline. Anti-Graffiti Coatings. http://www.graffitihotline.co.uk/graffiticoatings.htm

[7] Spiegelman, S. (1983) Striking Back at Graffiti. Essays of an Information Scientist, 6, 247 252.

[8] (2008) State of California. http://articles.latimes.com/2001/may/15/local/me-63714

[9] Bentley, W. (1997) Graffiti Control by Enforcement and Design. The First National Conference on Graffiti Control, Western Australia, 4 September 1996, 31-39.

[10] Panneerselvam, R. (2012) Engineering Economics. Thirteenth Edition, PHI Learning Private Limited, New Delhi.

[11] Teng, H. (2009) Evaluation of Graffiti Countermeasures on Highways. Final Report, Submitted to Nevada Department of Transportation.

[12] (2008) Lowe's Website. http://www.lowes.com/c/Fencing-gates-Building-supplies 


\section{Appendix}

\section{Survey Questionnaire}

\section{Graffiti Removal}

1) Do you have routine maintenance operations to remove graffiti, separating from other highway maintenance activities?

$\square$ Yes $\quad \square$ No

2) What kind of communication and information sharing should be required between the following divisions for graffiti removal and countermeasures?

Planning and maintenance:

Design and maintenance:

Construction and maintenance:

3) Rank the following graffiti removal techniques for each of the structures bridges, sound walls, retaining walls and traffic signs with 1 being the most cost-effective and 7 being the least cost-effective

Graffiti Removal Technique Bridges Sound Walls Retaining Walls Traffic Signs
High-pressure water sprays
Repainting the surface
Sandblasting
Paint remover: solvents
Paint remover: alkalis
Coating/resurface agents
Laser technology

4) What kind of instruments do you use to scan the colors for selecting the color that matches with the base color?
$\square$ No such instruments $\quad \square$ Electronic Spectrometers $\quad \square$ Color sensors
$\square$ Others (Please specify

5) What kind of graffiti abatement policies do you have?

$\square 24$ hrs abatement policy $\square 48$ hour abatement policy

$\square 72$ hour abatement policy $\square$ Others (please specify

6) Which of the following ways are you using to receive graffiti reports?

$\square$ Telephone $\quad \square$ Email $\square$ Both

$\square$ Other (please specify

7) In which way do you advertise the graffiti hotline number? 


\section{Graffiti Prevention}

8) What are the specific colors of paints that can be applied on the surfaces so that graffiti on these colors may not stand out longer?
$\square$ No such colors
$\square$ Brick red
$\square$ Brown
$\square$ Grey

$\square$ Others (please specify

9) What are the major textures for the following highway infrastructures?

$\square$ Bridges: Piers

\section{Girders}

Abutments

Beams

$\square$ Sound walls

$\square$ Retaining walls

$\square$ Traffic signs

10) What are the different anti-graffiti coatings you are applying for?

\begin{tabular}{|c|c|c|c|}
\hline & $\begin{array}{c}\text { Sacrificial } \\
\text { (If yes, give products) }\end{array}$ & $\begin{array}{l}\text { Non-Sacrificial } \\
\text { (If yes, give products) }\end{array}$ & $\begin{array}{c}\text { Others } \\
\text { (Specify the products) }\end{array}$ \\
\hline Piers & & & \\
\hline \multicolumn{4}{|l|}{ 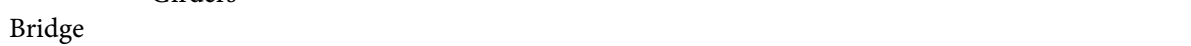 } \\
\hline Abutments & & & \\
\hline Beams & & & \\
\hline \multicolumn{4}{|l|}{ Sound Walls } \\
\hline \multicolumn{4}{|l|}{ Retaining Walls } \\
\hline Traffic Signs & & & \\
\hline
\end{tabular}

11) Do you have any countermeasures to prevent touching the structures such as?

Bridges $\square$ Unique anti-graffiti panel on the girder of bridges (See cover page)

$\square$ Others (please specify)

Sound Walls $\square$ Putting trellis to climb plants on walls

$\square$ Others (please specify)

$\underline{\text { Retaining Walls }} \square$ Putting trellis to climb plants on walls

$\square$ Others (please specify)

$\underline{\text { Traffic Signs }} \square$ Please specify

12) Do you have any countermeasures to prevent taggers accessing to structures such as?

Bridges $\square$ Arranging chain link fencing at the top and corners of bridges

$\square$ Others (please specify 
Sound Walls $\square$ Planting thorny shrubs

$\square$ Limiting access to roofs by moving dumpsters away from walls

$\square$ Landscaping options

$\square$ Arranging fencing

$\square$ Others (please specify

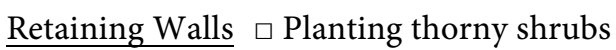

$\square$ Limiting access to roofs by moving dumpsters away from walls

$\square$ Landscaping options

$\square$ Arranging fencing

$\square$ Others (please specify

Traffic Signs $\square$ Rat guards

$\square$ Concertina wire

$\square$ Cobra shields

$\square$ Metal collars (on the posts of the sign structures)

$\square$ Others (please specify

13) Do you have any differentiation between reinforced concrete bridges and steel bridges in arranging fencing to deter the access of taggers?

$\square$ Yes $\quad \square$ No

If yes, please specify

14) Do you have any sign shop manufacturing graffiti protection for existing sign structures?

$\square$ Yes $\quad \square$ No

15) Do you have any design policy that sign structures must be located at least ten feet from any bridge or wall structure?

$\square$ Yes $\quad \square$ No

16) Did you grant permissions to other agencies (city, county, private firms) to clean graffiti on sound walls on your DOT Right of Way?

$\square$ Yes $\quad \square$ No

17) Do you use security cameras on graffiti-prone sites?

$\square$ Yes $\quad \square$ No

18) What are the issues that are to be considered in the process of installing security cameras?

$\square$ Reliability $\square$ Cost $\square$ Vandalism

$\square$ Others (please specify

19) Do you plan to add lighting to promote natural surveillance?

$\square$ Yes $\square$ No 
20) Do you have any civilian volunteer patrol groups, which call highway patrol groups and give witness to them when there is a "tagging" in progress?

$\square$ Yes $\quad \square$ No

21) Do the local schools in your state have any cooperative relation with your DOT in getting rid of graffiti?

$\square$ Yes $\quad \square$ No

22) Rank the effectiveness of following educational activities against graffiti with 1 as the most effective and $\mathbf{5}$ as the least effective for different levels of school.

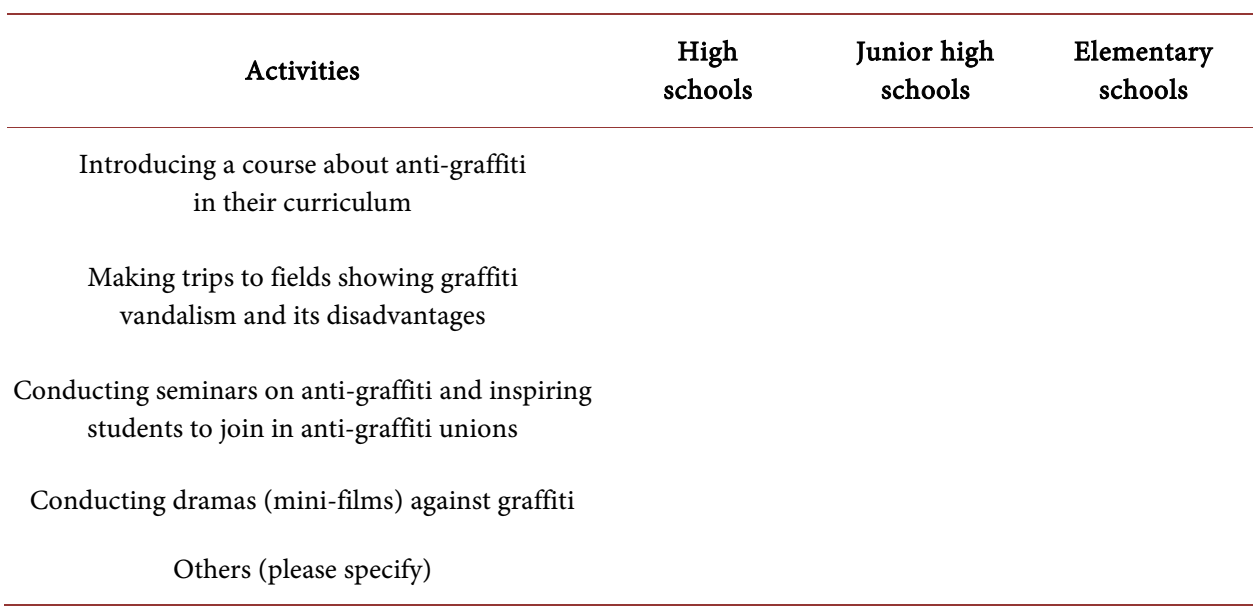

23) How does your state DOT get help from neighborhood community associations in preventing graffiti on highway infrastructures?

$\square$ Having meetings with their community associations against graffiti

$\square$ Disseminating anti-graffiti information bulletin (contains anti-graffiti hot lines and website information) to their associations

$\square$ Encouraging graffiti reports from their communities

$\square$ Jointly organizing mural projects

$\square$ Others (please specify

24) How does your DOT get help from police in preventing graffiti on highway infrastructures?

$\square$ Providing police with data regarding tagger gangs

$\square$ Police keeps eye also on the areas beyond the roads (surveillance)

$\square$ Helping police conduct counseling programs to taggers to get change in their attitude

$\square$ Others (please specify

25) How does your state DOT get help from local government agencies (city, county, etc.) to fight against graffiti on highway infrastructures?

$\square$ Having meetings with anti-graffiti coalition regularly 
$\square$ Exchanging ideas and information about graffiti

$\square$ Jointly organizing mural projects

$\square$ Others (please specify

26) What are the different options of punishing taggers in your state?

$\square$ Putting them in jails (range of jail period

$\square$ Charging fines (range of penalties/fines

$\square$ Making them involved in community service (No. of hrs/days of service

$\square$ Others (please specify

27) On what criteria, taggers will be punished in jails?

$\square$ The amount of graffiti they made. If chosen, specify the amount

$\square$ Frequency of recurrence of graffiti vandalism. If chosen, specify the frequency

$\square$ Age of taggers. If chosen, specify the age

$\square$ Others (please specify

28) On what criteria, taggers will be punished by charging fines/penalties?

$\square$ The amount of graffiti they made. If chosen, specify the amount

$\square$ Frequency of recurrence of graffiti vandalism. If chosen, specify the frequency

$\square$ Age of taggers. If chosen, specify the age

$\square$ Others (please specify

29) On what criteria, taggers will be punished to involve in community service?

$\square$ The amount of graffiti they made. If chosen, specify the amount

$\square$ Frequency of recurrence of graffiti vandalism. If chosen, specify the frequency

$\square$ Age of taggers. If chosen, specify the age

$\square$ Others (please specify

30) Do you have any taxes on graffiti making tools in your state?

$\square$ Yes $\quad \square$ No

31) In what way, graffiti vandalism can be considered from your agency prospective?

$\square$ Felony $\quad \square$ Misdemeanor

32) Are you practicing the CPTED (Crime Prevention Through Environmental Design) Concept for graffiti prevention? (CPTED includes strategies like natural surveillance and access control etc).

$\square$ Yes $\quad \square$ No

33) Do you think that aesthetic enhancement of structures can mitigate graffiti vandalism?

$\square$ Yes $\quad \square$ No 
34) What is the annual graffiti control expenditure for your state in the following years?

2005

2006

2007

35) Do you collect data regarding when and where graffiti occur on a daily basis?

$\square$ Yes

$\square$ No

36) Do you store the data you collected in computer and use them for scheduling and routing for graffiti removal?

$\square$ Yes $\square$ No

37) Do you have any written materials on graffiti countermeasures for highway infrastructures?

$\square$ Yes $\square$ No

Submit or recommend next manuscript to SCIRP and we will provide best service for you:

Accepting pre-submission inquiries through Email, Facebook, LinkedIn, Twitter, etc.

A wide selection of journals (inclusive of 9 subjects, more than 200 journals)

Providing 24-hour high-quality service

User-friendly online submission system

Fair and swift peer-review system

Efficient typesetting and proofreading procedure

Display of the result of downloads and visits, as well as the number of cited articles

Maximum dissemination of your research work

Submit your manuscript at: http://papersubmission.scirp.org/

Orcontact jtts@scirp.org 